\title{
Necessity of Magnetic Resonance Imaging (MRI) using an appropriate sequence for diagnosis of trigeminal neuralgia associated with intracranial tumor
}

\author{
Yoko Yamazaki ${ }^{*}$, Tomoko Niimi ${ }^{1}$, Yuko Ando ${ }^{1}$, Daisuke Tomizawa ${ }^{1}$, Masahiko Shimada ${ }^{2}$ \\ ${ }^{1}$ Orofacial Pain Clinic, Tokyo Medical and Dental University Dental Hospital, Tokyo, Japan \\ ${ }^{2}$ Orofacial Pain Management, Oral Restitution, Oral Health Sciences, Graduate School of Medical and Dental Sciences, Tokyo \\ Medical and Dental University, Tokyo, Japan \\ Email: yamazaki-yo.ofpm@tdm.ac.jp
}

Received 18 November 2013; revised 19 December 2013; accepted 28 December 2013

Copyright (C) 2013 Yoko Yamazaki et al. This is an open access article distributed under the Creative Commons Attribution License, which permits unrestricted use, distribution, and reproduction in any medium, provided the original work is properly cited.

\begin{abstract}
Aims: Trigeminal neuralgia is generally caused by neurovascular compression. In rare cases intracranial tumors may also lead to this condition. The present study was conducted to identify clinical symptoms and testing methods that are useful for early detection of trigeminal neuralgia associated with intracranial tumor. Methods: Five patients with trigeminal neuralgia suspected to be due to intracranial tumor, who visited our department for the first time during the period between February 2007 and March 2009, were examined. We analyzed the medical records and MRI findings of these patients. The clinical symptoms of subjects were compared to those presented at the International Classification of Headache Disorders. Results: There were no feature symptoms to trigeminal neuralgia caused by intracranial tumors compared with trigeminal neuralgia in general. None of the patients complained of spontaneous headache and nausea, which are clinical symptoms characteristic of brain tumor. Head MRI at our hospital was the most accurate method to detect intracranial tumors. Finally four of five patients received brain surgery to remove tumors. Conclusion: Small tumors and roots of the trigeminal nerve may not create accurate images by regular head MRI. Therefore, MRI using the imaging sequence which enables accurate visualization of roots of the trigeminal nerve is essential to confirm the presence of tumors in patients with suspected trigeminal neuralgia.
\end{abstract}

Keywords: Trigeminal Neuralgia; Intracranial Tumor; Benign Tumor; MRI; Neurosurgery

${ }^{*}$ Corresponding author.

\section{INTRODUCTION}

Trigeminal neuralgia is an excruciating type of pain that occurs in the face and oral cavity. It greatly interferes with daily activities of patients, including eating and face washing. Neurovascular compression is a widely known cause of trigeminal neuralgia [1]. In rare cases intracranial tumors may also lead to this condition. For the treatment of trigeminal neuralgia associated with intracranial tumors, the tumors are often removed by neurosurgical procedures in order to eliminate pain [2]. However, the surgery must be performed early because complete removal of the tumor may become impossible or the surgery may damage other nerves as the size of the tumor increases.

In trigeminal neuralgia pain arises in the areas of the jaw, oral cavity and face; as a result some patients first visit a dentist for treatment of the condition. If clinical features or testing methods to identify trigeminal neuralgia caused by tumors were known, dentists could easily refer patients to neurosurgeons and this could contribute to early detection of tumors.

The present study was conducted to identify clinical symptoms and testing methods that are useful for early detection of intracranial tumors. We retrospectively examined the clinical symptoms and imaging tests of patients with trigeminal neuralgia treated at the Orofacial Pain Clinic, Tokyo Medical and Dental University Hospital of Dentistry, whose neuralgia was speculated to be caused by intracranial tumors.

\section{METHODS}

Five patients with trigeminal neuralgia suspected to be due to intracranial tumor, who visited our department for the first time during the period between February 2007 
and March 2009, were examined. The medical records and MR images of each patient were retrospectively analyzed. Data obtained from the medical record included sex, age, duration of disease before the first visit, past and current medical history, characteristics of pain and the diagnosis and treatment provided at our department and the Department of Neurosurgery. The clinical symptoms of subjects were compared to those of classical trigeminal neuralgia presented at the International Classification of Headache Disorders.

\section{RESULTS}

\subsection{Background of Patients}

All the patients were females. There was no particular tendency in their characteristics, such as age, duration of disease before the first visit to our department and past history (Table 1).

\subsection{Clinical Symptoms}

The clinical symptoms of trigeminal neuralgia reported by the subjects of this study were compared to those of classical trigeminal neuralgia presented at the Interna- tional Classification of Headache Disorders (Table 2). There was no feature unique to trigeminal neuralgia caused by intracranial tumors in the factors that induce pain as well as character and duration of pain. This condition did not greatly differ from trigeminal neuralgia in general. None of the patients complained of spontaneous headache or nausea, which are clinical symptoms characteristic of brain tumor. Only one patient reported dizziness.

All the patients also visited the Department of Neurosurgery, Tokyo Medical and Dental University Hospital of Medicine and were diagnosed with intracranial tumor. The diagnoses made at our department and at the Department of Neurosurgery are shown in Table 3. None of the subjects had clinical symptoms of brain stem tumor, such as hemiplegia and hearing loss.

\subsection{Effect of Drugs}

All five patients had received the prescription for carbamazepine, which was effective. However, in 4 cases the dose could not be increased due to adverse reactions, making it difficult to eliminate pain with this drug (Table 4).

Table 1. Background of patients.

\begin{tabular}{|c|c|c|c|c|}
\hline & Age & Sex & Duration of disease & Past history \\
\hline Case 1 & 24 & female & About 3 weeks & - \\
\hline Case 2 & 67 & female & About 3 years & $\begin{array}{c}\text { Transient ischemic attack } \\
\text { Drug eruption } \\
\text { (carbamazepine) }\end{array}$ \\
\hline Case 3 & 40 & female & About 2 years & - \\
\hline Case 5 & 63 & female & About 3 months & $\begin{array}{l}\text { Uterine myoma } \\
\text { Ischemic colitis } \\
\text { Hypertension }\end{array}$ \\
\hline
\end{tabular}

-: nothing particular.

Table 2. The comparixon between clinical symptoms of trigeminal neuralgia caused by intracranial tumors and classical trigeminal neuralgia.

\begin{tabular}{|c|c|c|}
\hline & Trigeminal neuralgia caused by intracranial tumors & Classical trigeminal neuralgia \\
\hline Pain inducing factor & $\begin{array}{ll}\text { - } & \text { Eating }(5 \text { cases }) \\
\text { - } & \text { Talking }(4 \text { cases }) \\
\text { - } & \text { Washing the face }(2 \text { cases }) \\
\text { - } & \text { Brushing the teeth }(2 \text { cases })\end{array}$ & $\begin{array}{l}\text { Trivial stimuli including washing, shaving, smoking, talking } \\
\text { and/or brushing the teeth (trigger factors) }\end{array}$ \\
\hline Character of pain & $\begin{array}{l}\text { - Unilateral location } \\
\text { - The first, second and/or third division of the trigeminal } \\
\text { nerve } \\
\text { - Intense, electric shock-like pain, shooting, stabbing }\end{array}$ & $\begin{array}{l}\text { - } \quad \text { Unilateral disorder } \\
\text { ne distribution of one or more divisions of the trigeminal } \\
\text { - } \quad \text { Brief electric shock-like pains } \\
\text { - Intense, sharp, superficial or stabbing }\end{array}$ \\
\hline Duration of pain & $\begin{array}{l}\text { - } \quad \text { Flashing ( } 4 \text { cases }) \\
\text { - } 2 \text { - } 3 \text { minutes }(1 \text { cases })\end{array}$ & Fraction of a second to 2 minutes \\
\hline Spontaneous pain & Aching pain (2 cases) & Dull background pain may persist in some long-standing cases \\
\hline
\end{tabular}


Table 3. Diagnosis at first visit, preoperative and postoperative diagnosis.

\begin{tabular}{|c|c|c|c|c|}
\hline & Diagnosis (first visit) & Diagnosis (neurosurgery) & Operation & Diagnosis (postoperative) \\
\hline Case 1 & Left trigeminal neuralgia (V1) & Schwannoma & - & - \\
\hline Case 2 & Left trigeminal neuralgia (V2) & Epidermoid & $\circ$ & Epidermoid \\
\hline Case 3 & $\begin{array}{l}\text { - Left trigeminal neuralgia (V3) } \\
\text { - Left persistent idiopathic facial pain }\end{array}$ & $\begin{array}{l}\text { Petrous bone } \\
\text { meningioma }\end{array}$ & ० & Meningioma \\
\hline Case 4 & $\begin{array}{ll}\text { - } & \text { Left trigeminal neuralgia (V3) } \\
\text { - } & \text { Left glossopharyngeal neuralgia }\end{array}$ & Cerebellopontine angle tumor & ० & Meningioma \\
\hline Case 5 & $\begin{array}{l}\text { - Right trigeminal neuralgia (V3) } \\
\text { - Glossodynia }\end{array}$ & Tumor nearby facial and trigeminal nerve & $\circ$ & Apophysis \\
\hline
\end{tabular}

In Case 1, operation was not performed. Thus, postoperative diagnosis was unknown.

Table 4. Medication and effect of drugs.

\begin{tabular}{|c|c|c|}
\hline & Drugs & Effect \\
\hline Case 1 & Carbamazepine (600 mg) & $\begin{array}{l}\text { - } \\
\text { - Re change of pain intensity } \\
\text { - } \quad \text { Drug eruption }\end{array}$ \\
\hline Case 2 & $\begin{array}{l}\text { Zonisamide }(100 \mathrm{mg}) \\
\text { Carbamazepine }(100-200 \mathrm{mg})\end{array}$ & $\begin{array}{l}\text { - Zonisamide failed to control of pain } \\
\text { - Carbamazepine made pain reduction } \\
\text { - Drug eruption (Carbamazepine) }\end{array}$ \\
\hline Case 3 & $\begin{array}{l}\text { Carbamazepine }(800 \mathrm{mg}) \\
\text { Zonisamide }(400 \mathrm{mg})\end{array}$ & $\begin{array}{l}\text { - Zonisamide failed to control of pain } \\
\text { - Carbamazepine made pain reduction } \\
\text { - Leukopenia (Carbamazepine) }\end{array}$ \\
\hline Case 4 & $\begin{array}{l}\text { Goreisan (TJ-17) }(7.5 \mathrm{~g}) \\
\text { Carbamazepine }(100-200 \mathrm{mg})\end{array}$ & $\begin{array}{l}\text { - Goreisan failed to control of pain } \\
\text { - Carbamazepine made pain reduction }\end{array}$ \\
\hline Case 5 & $\begin{array}{l}\text { Carbamazepine }(400 \mathrm{mg}) \\
\text { Goreisan }(\mathrm{TJ}-17)(7.5 \mathrm{~g}) \\
\text { Zonisamide }(200 \mathrm{mg}) \\
\text { Gabapentin }(1200 \mathrm{mg})\end{array}$ & $\begin{array}{l}\text { - } \quad \text { Carbamazepine made pain reduction } \\
\text { - } \text { Hepatic insufficiency (Carbamazepine) } \\
\text { - } \quad \text { Gabisamide failed to control of pain } \\
\text { Gabin made pain reduction }\end{array}$ \\
\hline
\end{tabular}

Goreisan (TJ-17) is Kampo: traditional Japanese herbal medicine.

In Case 1 administration of carbamazepine was discontinued due to drug eruption, but the relief from pain was obtained immediately after discontinuation and further drug therapy became unnecessary. In Cases 2, 3 and 5 the dose of carbamazepine could not be increased beyond the reported levels because of adverse reactions. Zonisamide was used instead of carbamazepine, but pain could not be adequately alleviated. Gabapentin was finally effective in Case 5, still this drug was impossible to eliminate the patient's pain. One patient (Case 4) refused to take carbamazepine prescribed at our department and therefore pain control by Goreisan (TJ-17) was started. Subsequently, when the patient was referred to the Department of Neurosurgery, carbamazepine was prescribed and the patient agreed to take it.

\subsection{Past Treatments and Imaging Tests}

Some patients underwent treatment at other healthcare facilities before visiting our department. These patients had received dental treatment, such as occlusal adjustment, root canal treatment of teeth in the area where pain occurred and extraction of the teeth was performed.
Moreover medical treatment such as infraorbital nerve block as well as head CT or MRI were execued. Patients were prescribed antimicrobial agents, antiinflammatory agents and carbamazepine. Although some patients underwent imaging tests, the results did not reveal any tumors. Two patients were diagnosed with trigeminal neuralgia, but they were treated with medication or nerve block without performing head MRI. In all patients intracranial tumors were detected for the first time when MRI was performed at our hospital.

\subsection{Neurosurgeries}

As a result of examination at the Department of Neurosurgery, brain surgery to remove tumors was performed in all cases except Case 1. The diagnoses after the surgeries are shown in Table 3 . In Case 5 craniotomy revealed that the object suspected to be a tumor was an apophysis, which was impossible to remove. After the surgeries pain disappeared in Cases 2, 3 and 4. Case 1 was followed up without surgery. In Case 5, pain was alleviated but did not disappear because neurovascular compression was slightly resolved; however, the apophy- 
sis could not be removed.

\section{DISCUSSION}

Trigeminal neuralgia is one of the most painful afflictions of humanity [3], which substantially lowers the patient's quality of life. It is roughly divided into classical and symptomatic trigeminal neuralgia [4]. Trigeminal neuralgia caused by tumors as examined in this study is a rare type of symptomatic trigeminal neuralgia and its overall incidence is low [5]. Ono et al. reported that among 243 patients with trigeminal neuralgia, pain was attributed to pontine angle tumors in 25 patients (10.3\%) [6]. Other studies reported that about $10 \%$ of trigeminal neuralgia cases were caused by brain tumors [2,7]. At our department about $2.9 \%$ of trigeminal neuralgia cases were caused by brain tumors during the study period.

All five patients examined in this study visited the Department of Neurosurgery and four of them later underwent craniotomy. After the tumors were removed, the pain disappeared in three patients, indicating that pain control in trigeminal neuralgia caused by intracranial tumors requires tumor resection. On the other hand, in Case 5 with a bony prominence compressing nerves, pain was alleviated but not eliminated after the surgery. The compression of the trigeminal nerve remained, because the bony prominence could not be resection.

Tumors that cause trigeminal neuralgia include schwannoma, meningioma and epidermoid cyst, which are mostly benign [8]. Because benign tumors grow slowly and are unlikely to cause intracranial hypertension, clinical symptoms such as nausea and dizziness do not develop so often [9]. However, when tumors grow and occupy a large volume in the vicinity of brain stem, they can not only affect the trigeminal nerve but also influence activities of daily life. Moreover, when tumors increase in size, complete resection would be difficult because of the possibility of damaging various nerves during the surgery. Therefore, it could be essential that early detection of intracranial tumors is performed and a continuous follow-up is necessary.

There were no characteristic clinical symptoms in this study. Other investigators reported that there was no clinical feature characteristic of trigeminal neuralgia caused by tumors [9]. Some reports suggest that vascular compression or tumoral compression produces the same pathologic findings.

Therefore, the present study indicates that it is difficult to speculate about the presence or absence of tumors based only on clinical symptoms.

The present study demonstrated that head MRI was the most accurate method to detect tumors. In the algorithm for diagnosis of trigeminal neuralgia proposed by Kleef et al., MRI is given high priority in the diagnostic procedure [10]. There is also a report suggesting that
MRI was useful in diagnosis of symptomatic trigeminal neuralgia $[11,12]$.

In our department head MRI is performed for almost all patients with suspected trigeminal neuralgia. The MRI device used in Tokyo Medical and Dental University Hospital (Magnetom Vision; Siemens, Erlangen, Germany) creates images with a magnetic force of 1.5 Tesla. Because early-stage tumors are small and roots of the trigeminal nerve occupy a very limited area, regular head MRI may not create accurate images. Therefore, MRI using an imaging sequence that allows for accurate visualization of roots of the trigeminal nerve would be necessary. We use fast imaging with steady-state precision (FISP) and constructive interference in steady state (CISS) as well as T1 and T2-weighted images. These imaging sequences use the following paramaters; FISP: 39/6.5 (repetition time msec/echo time msec), $20^{\circ}$ flip angle, CISS: $12.25 / 5.9,70^{\circ}$ flip angle on CISS. In particular CISS enables visualization of not only arteries but also veins [13]. In FISP and CISS we enlarge the image of the area of pons and visualize it with a slice width of 1 $\mathrm{mm}$. By doing so, we can see the details of the area of roots of the trigeminal nerve (Figure 1). Therefore, small tumors that cannot be confirmed by regular MRI could be detected using this method, so head MRI would be the most accurate method to detect intracranial tumors at our hospital whether or not patients are examined with regular MRI at other hospitals.

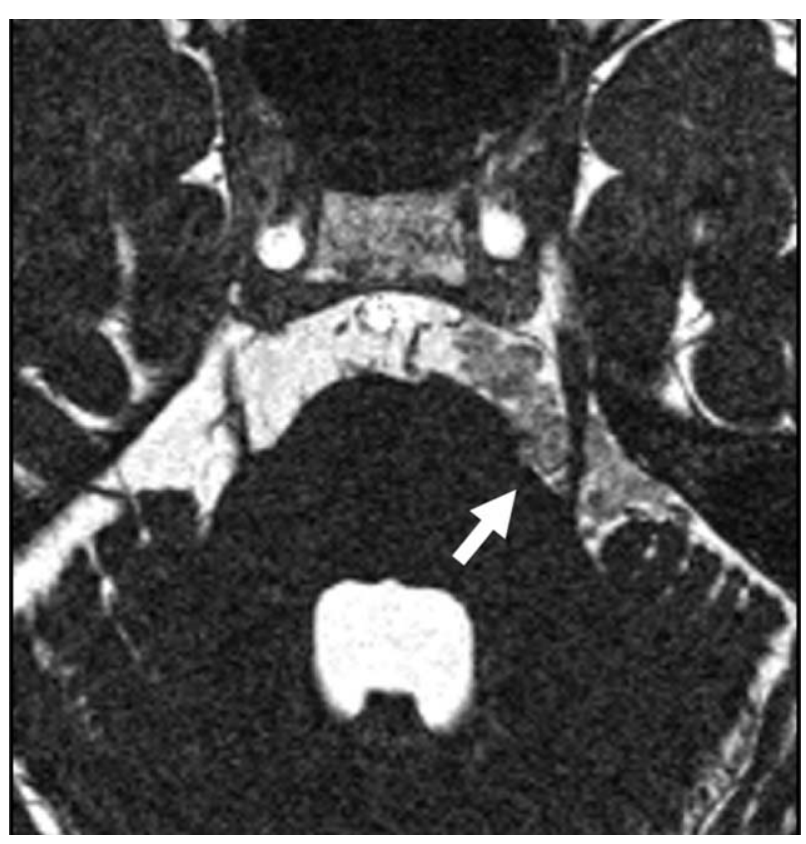

Figure 1. This image is MRI using an imaging sequence of CISS in Case 2. The arrow is an epidermoid tumor in the left cerebellopontine angle. On CISS imaging, the blood vessel and the nerve were shown as structures with a low signal intensity, and the cerebrospinal fluid was shown as a structure with a high signal intensity. The structures were clearly visualized. 
Thus, MRI using an appropriate imaging sequence seems to be indispensable for the detection of tumors.

\section{ACKNOWLEDGEMENTS}

The authors thank the Department of oral and maxillofacial radiology, Tokyo Medical and Dental Hospital of dentistry for presenting details of MRI.

\section{REFERENCES}

[1] Kabatas, S., Karasu, A., Civelek, E., Sabanci, A.P., Hepgul, K.T. and Teng, Y.D. (2009) Microvascular decompression as a surgical management for trigeminal neuralgia: Long-term follow-up and review of the literature. Neurosurgical Review, 32, 87-93. http://dx.doi.org/10.1007/s10143-008-0171-3

[2] Barker 2nd, F.G., Jannetta, P.J., Babu, R.P., Pomonis, S., Bissonette, D.J. and Jho, H.D. (1996) Long-term outcome after operation for trigeminal neuralgia in patients with posterior fossa tumors. Journal of Neurosurgery, 84, 818825. http://dx.doi.org/10.3171/jns.1996.84.5.0818

[3] Okeson, J.P. (2005) Neuropathic pains. In: Harmon, L., Ed., Bell's orofacial pains: The clinical management of orofacial pain, Sixth Edition, Quintessence, Tokyo, 449517.

[4] Headache Classification Subcommittee of the International Headache Society (2004) The international classification of headache disorders: 2 nd edition. Cephalalgia, 24, 9-160.

[5] Cirak, B., Kiymaz, N. and Arslanoglu, A. (2004) Trigeminal neuralgia caused by intracranial epidermoid tumor: Report of a case and review of the different therapeutic modalities. Pain Physician, 7, 129-132.

[6] Nakagawa, K., Aoyagi, M., Kawano, Y. and Ohno, K. (2009) Clinical and operative findings in patients with trigeminal neuralgia caused by brain tumors. No Shinkei Geka, 37, 863-871.
[7] Nomura, T., Ikezaki, K., Matsushima, T. and Fukui, M. (1994) Trigeminal neuralgia: Differentiation between intracranial mass lesions and ordinary vascular compression as causative lesions. Neurosurgical Review, 17, 5157. http://dx.doi.org/10.1007/BF00309988

[8] Love, S. and Coakham, H.B. (2001) Trigeminal neuralgia: Pathology and pathogenesis. Brain, 124, 2347-2360. http://dx.doi.org/10.1093/brain/124.12.2347

[9] Cirak, B., Kiymaz, N. and Arslanoglu. A. (2004) Trigeminal neuralgia caused by intracranial epidermoid tumor: Report of a case and review of the different therapeutic modalities. Pain Physician, 7, 129-132.

[10] van Kleef, M., van Genderen, W.E., Narouze, S., Nurmikko, T.J., van Zundert, J., Geurts, J.W. and Mekhail, N. (2009) 1. Trigeminal neuralgia. Pain Practice: The Official Journal of World Institute of Pain, 9, 252-259.

[11] Goh, B.T., Poon, C.Y. and Peck, R.H. (2001) The importance of routine magnetic resonance imaging in trigeminal neuralgia diagnosis. Oral Surgery, Oral Medicine, Oral Pathology, Oral Radiology, and Endodontics, 92, 424-429. http://dx.doi.org/10.1067/moe.2001.115130

[12] Gronseth, G., Cruccu, G., Alksne, J., Argoff, C., Brainin, M., Burchiel, K., Nurmikko, T. and Zakrzewska, J.M. (2008) Practice parameter: the diagnostic evaluation and treatment of trigeminal neuralgia (an evidence-based review): Report of the Quality Standards Subcommittee of the American Academy of Neurology and the European Federation of Neurological Societies. Neurology, 71, 11831190.

http://dx.doi.org/10.1212/01.wnl.0000326598.83183.04

[13] Yoshino, N., Akimoto, H., Yamada, I., Nagaoka, T., Tetsumura, A., Kurabayashi, T., Honda, E., Nakamura, S. and Sasaki, T. (2003) Trigeminal neuralgia: Evaluation of neuralgic manifestation and site of neurovascular compression with 3D CISS MR imaging and MR angiography. Radiology, 228, 539-545.

http://dx.doi.org/10.1148/radiol.2282020439 